\title{
Student-faculty interaction: Mediating between student engagement factors and educational outcome gains
}

\author{
$\mathrm{Hu}$, Yueh-Luen \\ Department of Education, National ChengChi University, Taiwan (joyhu@nccu.edu.tw) \\ Hung, Chao-Hsiang \\ Department of Education, National ChengChi University, Taiwan (aka0518@gmail.com)
}

Ching, Gregory S.

Graduate Institute of Educational Leadership and Development, Fu Jen Catholic University, Taiwan (gregory_ching@yahoo.com; 094478@mail.fju.edu.tw)

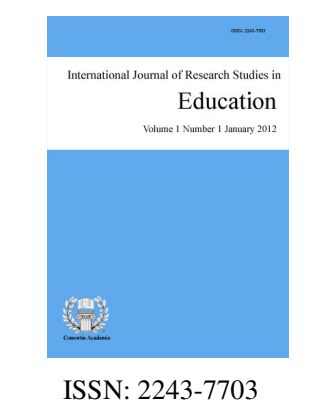

Received: 23 April $2014 \quad$ Revised: 20 November $2014 \quad$ Accepted: 24 November 2014

OPEN ACCESS

\begin{abstract}
The concepts of engagement have long been said to bring forth positive outcomes on students' university schooling. The reports of the National Survey for Student Engagement (NSSE) in the US have opened up various discussions on the benefits of such meaningful activities. On the other hand, the reemergence of the Chinese academies called Shuyuan or residential colleges have been spreading to both the East and West. It is said that the concept of having students living together with their faculty would instill a sense of belongingness that fosters learning. More important, both models of learning have within them the notion of student-faculty interactions. To dwell further on these concepts, the current study shall focus on the analysis of residential college students in Taiwan. A total of 724 students from four key universities that practices the model of residential colleges were surveyed. Structured equation modelling was accomplished resulting in the verification of a model of learning. Results show that student-faculty interaction successfully mediated the effects between the student engagement factors and students' educational outcome gains. The current results further provided an empirical proof of the importance of quality student and faculty communications and interactions. The current study hopes that the findings will be able to help educational administrators, policy makers, and researchers in designing future curriculum programs that fosters meaningful learning.
\end{abstract}

Keywords: student engagement; student-faculty interaction; residential colleges; Shuyuan; academies; educational outcome gains 


\section{Student-faculty interaction: Mediating between student engagement factors and educational outcome gains}

\section{Introduction}

During the turn of the 20th century, the concept of students' school engagement have become an important topic of discussion (Hu \& Ching, 2012; Hu, Ching, \& Chao, 2012). More important are the series of studies focusing on the National Survey of Student Engagement (NSSE) by Kuh and his associates (Kuh, 2001, 2003, 2009; Kuh, Cruce, Shoup, Kinzie, \& Gonyea, 2008). These series of studies reported various findings brought about by five effective educational practices, such as: level of academic challenge, active and collaborative learning, student-faculty interaction, enriching educational experiences, and supportive campus environment. The totality of these experiences are said to outweigh the perceived benefits of which institution students attend (Kuh, 2009). This means that whether what school students are enrolled in, the quality of educational experiences matters the most.

The inherent ideas within student engagement are the purposeful activities that are geared towards a wide range of student outcomes, such as persistence, satisfaction, achievement, and academic success (Pascarella \& Terenzini, 1991, 2005). Such notion of student engagement explains the various indications that even in within a challenged school district students are able perform better (Lawson \& Lawson, 2013). To make it simpler, the idea behind student engagement is that the more students spend time engaging with a subject, the more they should be able to understand and learn from it. Hence, learning takes place. More important, when students are interacting more with their peers and faculty regarding their lessons, the more students are able to apply their learning.

Looking into the ideas within Shuyuan, Chinese academies or residential colleges, wherein students and faculty learns and lives together as a community (Hu, Hung, Ching, \& Liao, 2013). This concept can be traced back to ancient Chinese history from the East, while the prototype colleges of the University of Oxford and Cambridge from the West. As early as during China's Tang Dynasty (AD 618-907), the concepts of Shuyuan started and proceed to become the dominant educational institution during the Song Dynasty (AD 960-1279); these institutions eventually played a significant role in shaping China's higher education (Min, 2004, p. 56). Within the Shuyuan model of education, freer discussion and debates are undertaken by the students and their mentors (Qiang, 2012, p. 453). More important, is the notion that a students are guided (or instructed) by one or more scholars (or mentors/faculty) (Hawkins, 2013, p. 59) Actually, there is since a revival of such practices in China's current higher education system (Wen, 2014).

In reality, the Chinese academies or Shuyuan is actually very similar to the early European concepts of residential colleges (Hayhoe, 1989). In that era, educational institutions are not just considered a place for teaching and learning, but are noted as a place where students and teachers lived and learn together (Ryan, 1993). In today's western higher education system, the concepts of Shuyuan or residential colleges can be found in the form of decentralized academic societies composed of faculty and student members (Duke, 1996). Similar to the Chinese models, residential colleges practices the concepts of having freshmen students residing with their seniors. These enriching educational experiences is found to be crucial in assisting the students' academic, social, or personal development (Durrani \& Sohaib, 2009). In essence, the concept of Shuyuan as applied to the East, while residential colleges (or living-learning center, theme house, and residential learning community) of the West both promises a type of interaction amongst teachers and students that fosters educational development. It is hoped that the current study shall provide a more empirical point of view with regards to the actual effects of such interaction.

With the primary focus of understanding the role of student-faculty interaction with the residential model of 
Student-faculty interaction: Mediating between student engagement factors and educational outcome gains

learning; the following section of this paper shall focus on the literature review of the student-faculty interaction, while followed by the methodology section. Then after the statistical results and discussions together with its implications are given; while the concluding section provides some final concerns for future studies and researches.

\section{Student-faculty interaction}

Dunleavy and Milton (2009) mentioned that the change in the role of teachers (faculty); perhaps a newer role for teachers themselves, are quite crucial in fostering effective teaching and transforming the learning environments. This fact further strengthens the importance of faculty in the academic lives of students. Student-faculty interaction is actually the quality of communication between student and faculty (Kuh, 2001, 2009). Quite simple yet deep in its meaning and implications; Pascarella and Terenzini (1977) started to test the various types of student-faculty interactions. Among the six reasons why students interact with their faculty, namely: to get basic information and advice about my academic program, to discuss matters related to my future career, to help resolve a disturbing personal problem, to discuss intellectual or course-related matters, to discuss a campus issue or problem, and to socialize informally (Pascarella \& Terenzini, 1977, p. 543), statistical analysis show that students discussion with regards to intellectual or course-related matters have the highest predictive power for students who will persists in their studies. Hence, as students interact academically with their faculty, learning happens.

The early findings of student-faculty interaction studies noted that the quality of engagement matters (Kuh $\& \mathrm{Hu}, 2001)$. Endo and Harpel (1982) mentioned the importance of student-faculty interaction as reflected on students' intellectual and personal (including social) outcomes gains during college. There findings suggest that student-faculty interactions must not be limited to the formal academic advising. These interactions should also include the informal; friendly contacts that are more on a personal level (Endo \& Harpel, 1982; Fusani, 1994; Lamport, 1993). In addition, these out-of-class contacts are said to be able to foster students' motivation (Jaasma \& Koper, 1999). More important, informal student-faculty interactions are able to help students improved their overall attitudes toward the school, academic achievement, intellectual and personal development (Pascarella, 1980).

Some early studies also hinted the existence of gender differences within the student-faculty interaction that leads to different classroom performances (Cornelius, Gray, \& Constantinople, 1990). More recent studies even further the findings of the differences within frequency of student-faculty interaction across students' race, gender, and social classes (Kim \& Sax, 2009; Lundberg \& Schreiner, 2004). Such findings are a bit alarming, since faculty should not differentiate the students because of their ethnicity or gender. As with the quality of student-faculty interaction matters, it would be fair that faculty should be able to provide equal amount of time to all of their students. In addition, some studies also mentioned that the provision of ample space (or location) wherein faculty are able to meet students and talk are also crucial in establishing quality student-faculty interaction (Zweigenhaft, 1976).

In a more recent study, it is proposed that faculty should take advantage of various social-network media to further the student-faculty interactions medium and opportunity (Li \& Pitts, 2009). Laird and Kuh (2005) reported that information technology plays an important role in enhancing effective student-faculty interaction. A study actually reported that students nowadays preferred the digital format for student-faculty interaction ( $\mathrm{Li}$, Finley, Pitts, \& Guo, 2011). In addition, the study suggests that the communication technology need not be very fancy (multi-media rich) even with just the use of email for communication is considered effective (which has been around for a very long time), as long as students are able to get an on-time reply, students are satisfied.

Cox and Orehovec (2007) found out that within the model of residential learning five distinct interactions are present, namely: disengagement, incidental contact, functional interaction, personal interaction, and mentoring. These findings suggest that almost all types of student-faculty interactions have a positive effect on 
students. Even the non-academic informal interactions between faculty and students are said to be able to provide meaningful results. Furthermore, Cotten and Wilson (2006) mentioned that there are three distinct issues with regards to student-faculty interactions, such as: the frequency and nature of the interactions, the impact of academic and social interactions, and the lack of student cognition towards the institution. Although their findings also noted that most students prefer not to interact with their faculty. Not to mention the even minimal contact with faculty outside the classroom. In reality, students are not aware that interactions have an overall positive impact on their academic studies (Cotten \& Wilson, 2006).

In light of the aforementioned issues, it seems that students must at first be able to have an environment wherein student-faculty interactions are seen as a normal day to day activity. In addition, the quality and frequency of the interactions should also be maintained no matter what type of medium it may be, or whether it is in-class or out-class (informal). Therefore, the current study shall provide the findings of the experiences of residential colleges in Taiwan that practices the concepts of student-faculty interactions.

\section{Methodology}

The current study uses the statistical method of structured equation modelling in testing the relational model of student-faculty interaction within the Shuyuan in Taiwan. Structured equation modelling is a highly used tool in testing relationships among the latent and observes variables (Schreiber, Stage, King, Nora, \& Barlow, 2006). The framework of the study primarily builds on the construct of a dataset called the Taiwan's Higher Education Students Survey, wherein Hu et al. (2012) managed to develop a Taiwan Student Engagement Model. In addition, the current study also uses the construct of the NSSE (Kuh, 2001, 2009) selected and grouped together under the five educational benchmark practices and three educational outcome gains factors. Lastly, local contextual items that are unique with the Shuyuan model of learning are also included.

\subsection{Hypothesis}

For the current study, it is hypothesized that the new model of learning in Shuyuan or residential colleges in Taiwan are mediated by the student-faculty interaction. Let us assume that student engagement factors as the latent independent variable, student-faculty interaction as the latent mediator and the educational outcome gains as dependent variables. Note that within the study Shuyuan and residential colleges are interchangeably used, however, pertains to the same concepts. Figure 1 shows the hypothesized mediated model for the residential college students in Taiwan. The initial hypotheses are as follows:

Dypothesis 1. For residential college students, both student engagement and student-faculty interaction have significant positive effect on educational outcome gains.

Dypothesis 2. For residential college students, student-faculty interaction mediates the relationship between student engagement and educational outcome gains.

\subsection{Participants}

The current study involved 724 undergraduate students enrolled in residential college from National Tsing Hua University (37.7\%), Tung Hai University (20.5\%), National Chung Cheng University (17.4\%), and National Cheng Chi University (24.4\%). The sample included 440 (60.8\%) women and 284 (39.2\%) men. Of the participants, $30.8 \%$ were freshmen, $26.1 \%$ were sophomores, $26.1 \%$ were juniors, and $17.0 \%$ were seniors. For the various background information of the four residential colleges used in the current study please read Hu et al. (2013) wherein a comparison of the various objectives and strategies of four key institutions are accomplished.

\subsection{Measures}

Student engagement (SE) is used to describe what college students are doing. Four observed variables were 
Student-faculty interaction: Mediating between student engagement factors and educational outcome gains used to measure the latent variable student engagement, including Active and collaborative Learning (ACL), Enriching Education Experiences (EEE), Cross Field Learning (CFL), and Citizenship. Within each observed variables, a subscale of 4 to 6 items were used. All of the items use a 7-point Likert scale ranging from 1 to 7. Four scales are reliable and valid, while the coefficient alpha ranging from .70 .89 and the explained variance ranging from $51 \% \sim 71 \%$.

Student-faculty interactions (SFI) are the factors used to describe the quality of interactions between students and faculty. Five items were used to measure the latent variable student-faculty interaction, sample items are teachers are able to provide written or oral feedbacks for my school works. All of the items use a 7-point Likert scale ranging from 1 to 7 . Reliability of the scale is computed to have a coefficient alpha of .86, while the explained variance is $78 \%$.

Educational outcome gains (EOG) are the items use to describe what college students have learned. Four observed variables were used to measure the latent variable educational outcome gains, including General Education Gains (GEG), Practical Competence Gains (PCG), and Personal Social Gains (PSG). Each of the observed variables are composed of subscale with 3 to 6 items, all of the items use a 7-point Likert scale ranging from 1 to 7 . Four scales are reliable and valid with the coefficient alpha ranging from .82 .90, and the explained variance ranging from $52 \% \sim 73 \%$.

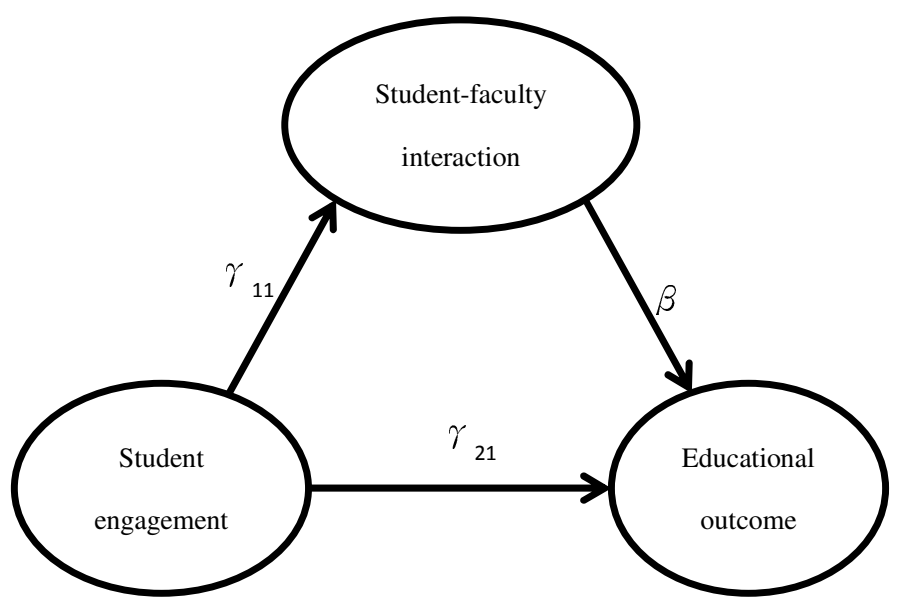

Figure 1. Hypothesized mediated model

\subsection{Data analysis}

The collected sample was then separated into two parts using random distribution as follows: $33 \%$ sample, $n=241 ; 67 \%$ sample, $n=483.33 \%$ sample size was used in the measurement model (for the computation of the Confirmatory Factor Analysis, CFA), while the remaining 67\% sample size was used in the structure model (path analysis and mediation test). Descriptive statistics and correlation estimated using the SPSS version 21, while the composite reliability (CR) and average variance extracted (AVE) were used to prove the reliability and validity of measurement model. Structure model was used to explain the relationship and effect among latent variables. Structure equation modeling was estimated using the maximum-likelihood method in the AMOS 20 program (Arbuckle, 2011).

\section{Results}

\subsection{Preliminary analyses}

Means, standard deviations (SD), and zero-order correlations for the 11 measured variables are shown in Table 1. Since the numbers of items are not equal in each of the variable, standard practice is to show the mean 
Hu, Y.-L., Hung, C.-H., \& Ching, G. S.

values instead. Table 1 shows that all of the means of observed variables ranging from 3.67 5.18, while SD ranging from 1.00 1.73. In addition, the multivariate normality test was accomplished to test whether the data met the assumptions for normality underlying the maximum-likelihood procedure used to test the models. The results of the multivariate normality test indicated that the data are within the normal range, while multivariate kurtosis of $<3$. Therefore, maximum-likelihood method is appropriate.

Table 1

Means, standard deviations, and zero-order correlations matrix $(N=724)$

\begin{tabular}{lcccccccccccccc}
\hline Variables & Mean & $\boldsymbol{S D}$ & 1 & 2 & 3 & 4 & 5 & 6 & 7 & 8 & 9 & 10 & 11 & 12 \\
\hline ACL & 5.00 & 1.13 & 1 & & & & & & & & & & \\
EEE & 4.81 & 1.00 & .62 & 1 & & & & & & & & & \\
CFL & 5.11 & 1.13 & .58 & .58 & 1 & & & & & & & & \\
Citizenship & 3.67 & 1.40 & .47 & .58 & .49 & 1 & & & & & & & \\
SFI_1 & 4.15 & 1.73 & .28 & .28 & .20 & .23 & 1 & & & & & & \\
SFI_2 & 4.81 & 1.52 & .39 & .34 & .31 & .23 & .67 & 1 & & & & & \\
SFI_3 & 4.51 & 1.56 & .33 & .31 & .26 & .23 & .54 & .64 & 1 & & & & \\
SFI_4 & 4.82 & 1.54 & .34 & .31 & .31 & .20 & .51 & .56 & .62 & 1 & & & \\
SFI_5 & 4.75 & 1.67 & .37 & .29 & .31 & .24 & .57 & .64 & .67 & .64 & 1 & & & \\
GEG & 4.68 & 1.08 & .41 & .49 & .41 & .37 & .38 & .48 & .51 & .48 & .52 & 1 & & \\
PCG & 4.21 & 1.02 & .37 & .42 & .35 & .31 & .45 & .46 & .48 & .47 & .47 & .77 & 1 & \\
PSG & 5.18 & 1.10 & .42 & .44 & .44 & .31 & .35 & .49 & .52 & .50 & .51 & .85 & .70 & 1 \\
\hline \multicolumn{2}{l}{ Note. All values of correlation are significant $(p<.001)$} & & & & & & & & &
\end{tabular}

\subsection{Measurement model}

Before a structural model is tested, Anderson and Gerbing (1988) proposed the use of a CFA to examine whether the measurement model provides an acceptable fit to the data. Once an acceptable measurement model is developed, the structural model can be tested. As suggested by Tucker and Lewis (1973) and Byrne (2001) five fit indices were used to assess goodness of fit for the model. Table 2 shows the results of the model fit values. Such as: the goodness of fit index (GFI; values $>0.90$ which indicate good fit), the comparative fit index (CFI; values $>0.90$ which indicate good fit), the Tucker-Lewis Index (TLI; values $>0.90$ which indicate good fit), the non-normed fit index (NFI; values $>0.90$ which indicate good fit), and the root-mean-square error of approximation (RMSEA; values $<0.08$ which indicate good fit).

Table 2

Model Fit Indices

\begin{tabular}{cccc}
\hline Indices & Measurement model & Structural model & Criteria \\
\hline $\mathrm{N}$ & 241 & 483 & \\
$\chi^{2}$ & 92.62 & 178.07 & \\
$\mathrm{df}$ & 51 & 51 & $>.90$ \\
$\mathrm{GFI}$ & .94 & .95 & $>.90$ \\
$\mathrm{CFI}$ & .96 & .97 & $>.90$ \\
$\mathrm{TLI}$ & .95 & .96 & $>.90$ \\
$\mathrm{NFI}$ & .95 & .96 & $<.08$ \\
\hline RMSEA & .071 & .068 & \\
\hline
\end{tabular}

For the test of the measurement model resulted in a relatively good fit to the data with $\chi^{2}=115.03, \mathrm{df}=41$, $\mathrm{GFI}=.94, \mathrm{CFI}=.96, \mathrm{TLI}=.95, \mathrm{NFI}=.95$, and RMSEA $=.071$; while all of the standardized loadings of the measured variables on the latent variables were greater than .66 and statistically significant at $p<.001$ (please see Table 3). CR of the latent variables ranging from .84 .94, while the AVE ranging from .56 .84, both CR and 
Student-faculty interaction: Mediating between student engagement factors and educational outcome gains

AVE values are within the standard accepted value (Fornell \& Larcker, 1981; Hair, Anderson, Tatham, \& Black, 1998; Hair, Black, Babin, Anderson, \& Tatham, 2005; Hair, Black, Babin, \& Anderson, 2010). Therefore, all of the latent variables appear to have been adequately operationalized by their respective indicators. In addition, correlations among the independent latent variables, the mediator latent variable, and the dependent latent variables were all statistically significant with $p<.001$ (see Table 4).

Table 3

Factor loadings for the measurement model (33\% sample, $n=241)$

\begin{tabular}{|c|c|c|c|c|c|}
\hline Factor/Item & Standardized factor loading & error & $t$ & AVE & CR \\
\hline Student engagement (SE) & & & & .56 & .84 \\
\hline ACL & .77 & & & & \\
\hline EEE & .83 & 0.05 & 18.29 & & \\
\hline CFL & .73 & 0.06 & 16.35 & & \\
\hline Citizenship & .66 & 0.07 & 14.79 & & \\
\hline \multicolumn{6}{|c|}{ Student-faculty interaction (SFI) } \\
\hline SFI_1 & .72 & & & .62 & .89 \\
\hline SFI_2 & .80 & 0.06 & 17.45 & & \\
\hline SFI_3 & .81 & 0.06 & 17.56 & & \\
\hline SFI_4 & .77 & 0.06 & 16.77 & & \\
\hline SFI_5 & .82 & 0.06 & 17.88 & & \\
\hline \multicolumn{6}{|c|}{ Educational outcome gains (EOG) } \\
\hline GEG & .95 & & & .84 & .94 \\
\hline PCG & .91 & 0.03 & 26.56 & & \\
\hline PSG & .89 & 0.03 & 32.72 & & \\
\hline
\end{tabular}

Table 4

Correlations matrix for the measurement model (33\% sample, $n=241$ )

\begin{tabular}{llll}
\hline \multicolumn{1}{c}{ Latent Variables } & 1 & 2 & 3 \\
\hline 1. Student engagement(SE) & 1 & & \\
2. Student-faculty interaction (SFI) & .50 & 1 & 1 \\
3. Educational outcome gains (EOG) & .69 & .66 &
\end{tabular}

\subsection{Structural model for testing mediated effects}

Taking the factor student engagement as the latent IV, student-faculty interaction as the latent mediator, and the educational outcome gains as the dependent variables; the results showed a good fit for the model with $\chi^{2}$ $=178.07, \mathrm{df}=51, \mathrm{GFI}=.95, \mathrm{CFI}=.97, \mathrm{TLI}=.96, \mathrm{NFI}=.96, \mathrm{RMSEA}=.068$, while all the effect size of structural paths were computed to be of medium $\left(\gamma_{11}=.50, \beta_{1}=.48, \gamma_{21}=.37\right)$ and are significant with the significant value $p<.001$ (see Table 5).

Table 5

Bootstrap analysis of structural model (67\% sample, $n=483)$

\begin{tabular}{ccccccc}
\hline & Direct effect & \multicolumn{2}{c}{ Indirect effect } & \multicolumn{2}{c}{ Total effect } \\
\hline$\gamma_{11}$ & $\beta_{1}$ & $\gamma_{21}$ & $\gamma_{11} * \beta_{1}$ & $95 \%$ CI & $\gamma_{21}+\gamma_{11} * \beta_{1}$ & $95 \%$ CI \\
$.50^{* * *}$ & $.48^{* * *}$ & $.37 * * *$ & .24 & $.18 \sim .30$ & .61 & $.53 \sim .69$ \\
\hline Note. ${ }^{* * *} p<.001$ & & &
\end{tabular}

MacKinnon, Lockwood, Hoffmann, West, and Sheets (2002) uses various approaches in examining the 
mediation for consideration of Type I errors and statistical power. They found that the most often used strategy is the one used by Baron and Kenny (1986) which has the least power for both $\gamma_{11}$ and $\beta_{1}$ to be significant. In addition, many studies also uses the approach that relies on the Sobel test (1982) to examine the significance of the mediation effect $\left(\gamma_{11} * \beta_{1}\right.$ have to be significant). However, if there are evidences that the distribution of mediation effect is not normal; Sobel test, which assumes a normal distribution when examining the mediation effect, is not appropriate (MacKinnon \& Dwyer, 1993). Therefore, it suggested that the use of the bootstrap method can be a better way to examine mediation (Shrout \& Bolger, 2002). Bootstrap method acquires $95 \%$ of the confidence intervals (CI) for the indirect effect by resampling procedure. Based on central limit theorem, bootstrap method is robust even when the distribution of mediation effect is not normal. Using Shrout and Bolger (2002) suggested value, if $95 \%$ of the CI is used for the estimates of the indirect effects based on 5000 indirect effect estimates; which does not include zero, then it can be concluded that the indirect effect is statistically significant at the .05 level. Therefore, after the structural models were examined through the AMOS 20 program, the bootstrap procedure was used to test whether or not the indirect effects are statistically significant.

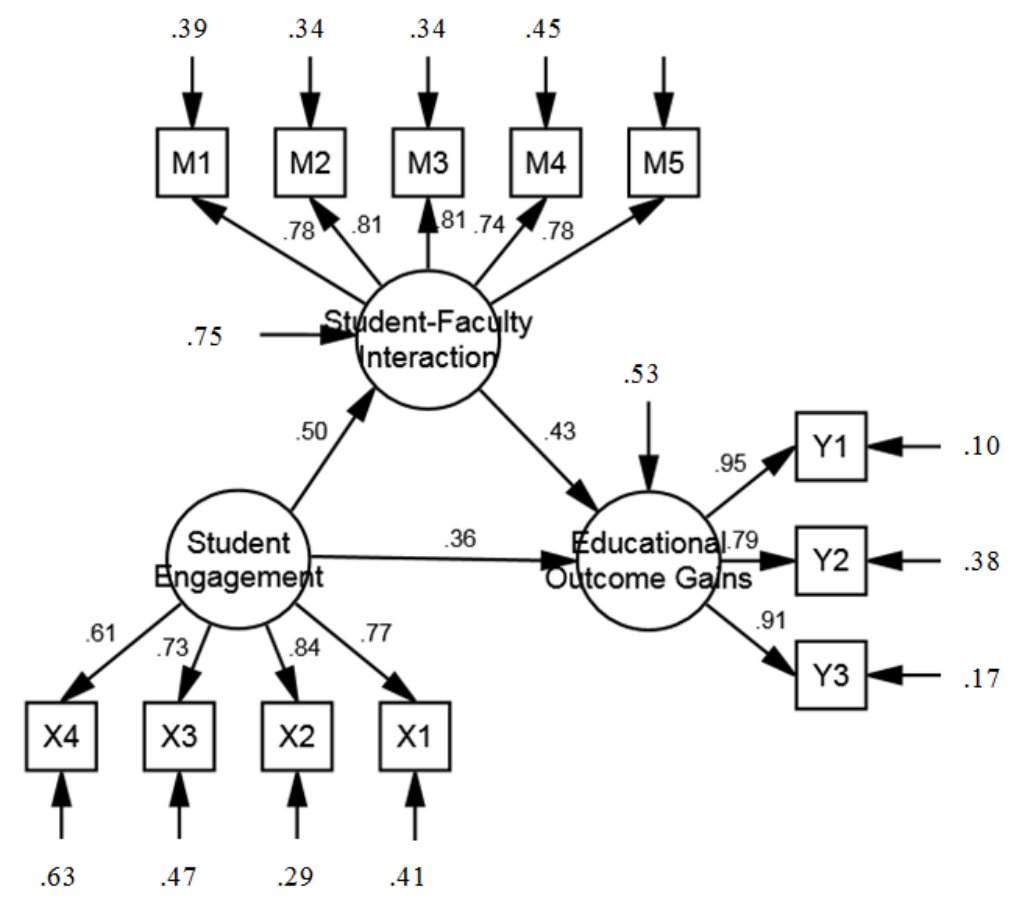

Wherein:

M1 : My teacher guides/assists me in accomplishing my school related tasks

M2 : My teachers provide me with written or oral feedbacks for my school works

M3 : My teachers give suggestions regarding my future career

M4 : When I have difficulty with my lessons, I know where to look for resources and/or ask for assistance

M5 : Besides academic related issues, my teachers also show concern toward other extracurricular activities

X1: Active and collaborative Learning (ACL)

$\mathrm{X} 2$ : Enriching Education Experiences (EEE)

X3: Cross Field Learning (CFL)

X4: Citizenship

Y1: General Education Gains (GEG)

Y2: Practical Competence Gains (PCG)

Y3: Personal Social Gains (PSG)

Figure 2. Structural model

Mediation effect is also referred to as the indirect effect $(\gamma 11 * \beta 1)$, which is .4 ; while the $95 \% \mathrm{CI}$ for the estimates of the indirect effects ranging from .18 .30 does not include zero. Therefore, it can be concluded that 
Student-faculty interaction: Mediating between student engagement factors and educational outcome gains

the indirect effect is statistically significant at the .05 level. For residential college students, student-faculty interaction plays a role as mediator between student engagement and educational outcome gains. Wherein the total effect is the summation of direct effect and indirect effect $(\gamma 21+\gamma 11 * \beta 1)$, the total effect is computed to be .61 , while the $95 \% \mathrm{CI}$ for total effects ranging from .53 .69 does not include zero. Hence, the total effect is statistically significant at the .05 level. In sum, the results of the structure model (see Figure 2) shows that the theory model can explain the educational outcome gains for Shuyuan or residential college students in Taiwan. Therefore, both of the proposed hypotheses are supported. In addition, according to Baron and Kenny (1986) if the direct effect is still significant, the model is considered a partial mediation, wherein there may be other effective mediator that can be taken into consideration in the future.

\section{Conclusion}

The current study uses the statistical method of structured equation modelling in providing an empirical explanation between the relationship of student engagement factors, student-faculty interaction, and educational outcome gains. As the study shows that the student-faculty interaction acts as a mediator between student engagement and educational outcome gains; denoting that the quality of interaction between faculty and students as instrumental for students' improvement. Such results imply that schools should create an atmosphere of positive and healthy student-faculty interactions. Even though that educational institution provide opportunities for active and collaborative learning and enriching education experiences, these engagement are enhanced with the help of student-faculty engagements.

As for the uniqueness of Shuyuan model of learning in Taiwan, it is noted that among the different colleges (4 residential colleges used in this study), key developmental focus of engagement are not that similar (Hu, Ching, \& Hung, 2015). However, the core method used is still the same, which is student-faculty interaction. Further studies can be made with the graduates of these academies, as the notion of student engagement is said to persists, comparison between the normal (traditional) educational systems' graduates should shed light in better understanding the effectiveness of Shuyuan and student-faculty interaction.

NOTE: This work is supported by the Taiwan National Science Council Project 101-2410-H-004-168-MY2

\section{References}

Anderson, J. C., \& Gerbing, D. W. (1988). Structural equation modeling in practice: A review and recommended two-step approach. Psychological Bulletin, 103(3), 411-423. http://dx.doi.org/10.1037/0033-2909.103.3.411

Arbuckle, J. L. (2011). IBM SPSS Amos 2.0 user's guide. Armonk, NY: IBM.

Baron, R. M., \& Kenny, D. A. (1986). The moderator-mediator variable distinction in social psychological research: Conceptual, strategic, and statistical considerations. Journal of Personality and Social Psychology, 51(6), 1173-1182. http://dx.doi.org/10.1037/0022-3514.51.6.1173

Byrne, B. M. (2001). Structural equation modeling with AMOS: Basic concepts, applications, and programming. New York, NY: Taylor and Francis Group.

Cornelius, R. R., Gray, J. M., \& Constantinople, A. P. (1990). Student-faculty interaction in the college classroom. Journal of Research \& Development in Education, 23(4), 189-190.

Cotten, S. R., \& Wilson, B. (2006). Student-faculty interactions: Dynamics and determinants. Higher Education, 51(4), 487-519. http://dx.doi.org/10.1007/s10734-004-1705-4

Cox, B. E., \& Orehovec, E. (2007). Faculty-student interaction outside the classroom: A typology from a residential college. The Review of Higher Education 30(4), 343-362. http://dx.doi.org/10.1353/rhe.2007.0033

Duke, A. (1996). Importing Oxbridge: English residential colleges and American universities. New Haven: Yale University Press.

Dunleavy, J., \& Milton, P. (2009). What did you do in school today? Exploring the concept of student engagement and its implications for teaching and learning in Canada. Toronto: Canadian Education 
Association.

Durrani, M., \& Sohaib, K. (2009). Bringing the residential college model to LUMS. Retrieved from http://web.lums.edu.pk/ sohaib/docs/ResidentialCollegeWhitePaper.Short.pdf

Endo, J. J., \& Harpel, R. L. (1982). The effect of student-faculty interaction on students' educational outcomes. Research in Higher Education, 16(2), 115-138. http://dx.doi.org/10.1007/BF00973505

Fornell, C., \& Larcker, D. (1981). Structural equation models with unobservable variables and measurement error. Journal of Marketing Research, 18(1), 39-50. http://dx.doi.org/10.2307/3151312

Fusani, D. S. (1994). "Extra-class" communication: Frequency, immediacy, self-disclosure, and satisfaction in student-faculty interaction outside the classroom. Journal of Applied Communication Research, 22(3), 232-255. http://dx.doi.org/10.1080/00909889409365400

Hair, J. F., Jr., Anderson, R. E., Tatham, R. L., \& Black, W. C. (1998). Multivariate data analysis. Englewood Cliffs, NJ: Prentice-Hall.

Hair, J. F., Jr., Black, B., Babin, B. J., Anderson, R. E., \& Tatham, R. L. (2005). Multivariate data analysis (6th ed.). Upper Saddle River, New Jersey: Prentice Hall.

Hair, J. F., Jr., Black, W. C., Babin, B. J., \& Anderson, R. E. (2010). Multivariate data analysis: A global perspective. Upper Saddle, NJ: Pearson.

Hawkins, J. N. (2013). East-west? Tradition and the development of hybrid higher education in Asia. In D. Neubauer, J. C. Shin \& J. N. Hawkins (Eds.), Dynamics of higher education development in East-Asia: Western dominance, Asian cultural heritage, economic development, and globalization (pp. 51-67). New York: Palgrave Macmillan. http://dx.doi.org/10.1057/9781137347374.0009

Hayhoe, R. (1989). China's universities and western university models. In P. G. Altbach \& V. Selvaratnam (Eds.), From dependence to autonomy: The development of Asian universities (pp. 25-61). Dordrecht, Netherlands: Kluwer Academic. http://dx.doi.org/10.1007/978-94-009-2563-2_2

Hu, Y.-L., \& Ching, G. S. (2012). Factors affecting student engagement: An analysis on how and why students learn. In 2012 Conference on creative education (pp. 989-992). Irvine, CA: Scientific Research Publishing.

Hu, Y.-L., Ching, G. S., \& Chao, P.-C. (2012). Taiwan student engagement model: Conceptual framework and overview of psychometric properties. International Journal of Research Studies in Education, 1(1), 69-90. http://dx.doi.org/10.5861/ijrse.2012.v1i1.19

Hu, Y.-L., Ching, G. S., \& Hung, C.-H. (2015). Comparison of concepts within the residential colleges in Taiwan. International Journal of Information and Education Technology, 5(12), 936-940. http://dx.doi.org/10.7763/IJIET.2015.V5.641

Hu, Y.-L., Hung, G.-C., Ching, G. S., \& Liao, C.-F. (2013). Reviving the concept of residential college in Taiwan: An introductory study. In International proceedings of economics development and research (Vol. 64, pp. 12-16). Singapore: IACSIT Press.

Jaasma, M. A., \& Koper, R. J. (1999). The relationship of student-faculty out-of-class communication to instructor immediacy and trust and to student motivation. Communication Education, 48(1), 41-47. http://dx.doi.org/10.1080/03634529909379151

Kim, Y. K., \& Sax, L. J. (2009). Student-faculty interaction in research universities: Differences by student gender, race, social class, and first-generation status. Research in Higher Education, 50(5), 437-459. http://dx.doi.org/10.1007/s11162-009-9127-x

Kuh, G. D. (2001). The national survey of student engagement: Conceptual framework and overview of psychometric properties. Bloomington, IN: Indiana University Center for Postsecondary Research and Planning.

Kuh, G. D. (2003). What we're learning about student engagement from NSSE. Change, 35(2), 24-32. http://dx.doi.org/10.1080/00091380309604090

Kuh, G. D. (2009). The national survey of student engagement: Conceptual and empirical foundations. New Directions for Institutional Research, 141, 5-21. http://dx.doi.org/10.1002/ir.283

Kuh, G. D., Cruce, T., Shoup, R., Kinzie, J., \& Gonyea, R. (2008). Unmasking the effects of student engagement on first-year college grades and persistence. The Journal of Higher Education, 79(5), 540-563. http://dx.doi.org/10.1353/jhe.0.0019

Kuh, G. D., \& Hu, S. (2001). The effects of student-faculty interaction in the 1990s. The Review of Higher Education 24(3), 309-332. http://dx.doi.org/10.1353/rhe.2001.0005

Laird, T. F. N., \& Kuh, G. D. (2005). Student experiences with information technology and their relationship to other aspects of student engagement. Research in Higher Education, 46(2), 211-233. http://dx.doi.org/10.1007/s11162-004-1600-y

Lamport, M. A. (1993). Student-faculty informal interaction and the effect on college student outcomes: A review of the literature. Adolescence, 28(112), 971-990. 
Student-faculty interaction: Mediating between student engagement factors and educational outcome gains

Lawson, M. A., \& Lawson, H. A. (2013). New conceptual frameworks for student engagement research, policy, and practice. Review of Educational Research, 83(3), 432-479. http://dx.doi.org/10.3102/0034654313480891

Li, L., Finley, J., Pitts, J., \& Guo, R. (2011). Which is a better choice for student-faculty interaction: Synchronous or asynchronous communication? [Electronic Version]. Journal of Technology Research, from http://www.aabri.com/manuscripts/10682.pdf

Li, L., \& Pitts, J. P. (2009). Does it really matter? Using virtual office hours to enhance student-faculty interaction. Journal of Information Systems Education, 20(2), 175-185.

Lundberg, C. A., \& Schreiner, L. A. (2004). Quality and frequency of faculty-student interaction as predictors of learning: An analysis by student race/ethnicity. Journal of College Student Development 45(5), 549-565. http://dx.doi.org/10.1353/csd.2004.0061

MacKinnon, D. P., \& Dwyer, J. H. (1993). Estimating mediated effects in prevention studies. Evaluation Review, 17(2), 144-158. http://dx.doi.org/10.1177/0193841X9301700202

MacKinnon, D. P., Lockwood, C. M., Hoffman, J. M., West, S. G., \& Sheets, V. (2002). Comparison of methods to test mediation and other intervening variable effects. Psychological Methods, 7, 83-104. http://dx.doi.org/10.1037/1082-989X.7.1.83

Min, W. (2004). The legacy of the past and the context of the future. In P. G. Altbach \& T. Umakoshi (Eds.), Asian universities: Historical perspectives and contemporary challenges (pp. 53-83). Baltimore, Maryland: John Hopkins University Press.

Pascarella, E. T. (1980). Student-faculty informal contact and college outcomes. Review of Educational Research, 50(4), 545-595. http://dx.doi.org/10.3102/00346543050004545

Pascarella, E. T., \& Terenzini, P. T. (1977). Patterns of student-faculty informal interaction beyond the classroom and voluntary freshman attrition. The Journal of Higher Education, 48(5), 540-552. http://dx.doi.org/10.2307/1981596

Pascarella, E. T., \& Terenzini, P. T. (1991). How college affects students: Findings and insights from twenty years of research (Vol. 1). San Francisco, CA: Jossey-Bass.

Pascarella, E. T., \& Terenzini, P. T. (2005). How college affects students: A third decade of research (Vol. 2). San Francisco: Jossey-Bass.

Qiang, Z. (2012). Is there an emerging Chinese model of the university. In R. Hayhoe, J. Li, J. Lin \& Q. Zha (Eds.), Portraits of 21 st century Chinese universities: In the move to mass higher education (Vol. 30, pp. 451-472). Dordrecht: Springer.

Ryan, M. B. (1993). Residential colleges: An historical context. In T. B. Smith (Ed.), Gateways: Residential colleges and the freshman year experience. Monograph Series Number 14 (pp. 11-19). Carolina: University of South Carolina.

Schreiber, J. B., Stage, F. K., King, J., Nora, A., \& Barlow, E. A. (2006). Reporting structural equation modeling and confirmatory factor analysis results: A review. Journal of Educational Research, 99(6), 323-337. http://dx.doi.org/10.3200/JOER.99.6.323-338

Shrout, P. E., \& Bolger, N. (2002). Mediation in experimental and non-experimental studies: New procedures and recommendations. Psychological Methods, 7(4), 422-445. http://dx.doi.org/10.1037/1082-989X.7.4.422

Sobel, M. E. (1982). Asymptotic confidence intervals for indirect effects in structural equation models. Sociological Methodology, 13, 290-312. http://dx.doi.org/10.2307/270723

Tucker, L. R., \& Lewis, C. (1973). A reliability coefficient for maximum likelihood factor analysis. Psychometrika, 38(1), 1-10. http://dx.doi.org/10.1007/BF02291170

Wen, X. (2014). The enlightenment of the spirit of ancient academy in the construction of modern academy [zhōng guó gǔ dài shū yuàn jīng shén duì xiàn dài dà xué shū yuàn zhì jiàn shè de;dì; dí qǐ shì]. Education and Teaching Research, 28(8), 26-30.

Zweigenhaft, R. L. (1976). Personal space in the faculty office: Desk placement and the student-faculty interaction. Journal of Applied Psychology, 61(4), 529-532. http://dx.doi.org/10.1037/0021-9010.61.4.529 
Hu, Y.-L., Hung, C.-H., \& Ching, G. S. 